\title{
Cinema and its relationship with merchandising at the beginning of the $21^{\text {st }}$ century \\ EI cine y su relación con el merchandising en el siglo XXI \\ Miguel Ángel Rivas Romero \\ Universidad de Málaga, España
}

\begin{abstract}
The cinema of the first two decades of the 21st century cannot be understood without the visual, technological, economic and cultural impact of blockbusters, linked in their transmedia dimension with a series of franchises: Harry Potter, Star Wars, Marvel. The digital revolution that began in 1999 (The Matrix and Episode l: The Phantom Menace) reached its zenith in 2019 with the premiere of Avengers: EndGame, breaking the box office. Thus, Disney, owner of LucasFilm, Pixar and Marvel Studios, reached the highest annual gross achieved by a film studio. Productions all premiered on the big screens of the world's cinemas financed with the sale of licenses for the commercialization of merchandising. The year 2020 will go down in history due to the global health crisis produced by Covid-19, the collapse of the health system, the confinement of the population, the closure of productive sectors, public and private services, sports, education and culture. At the same time, online sales businesses such as Amazon or audiovisual content platforms (Netflix, Disney or $H B O)$ were reaching subscriber numbers expected for the not so near future. While all the cinemas in the world closed their theaters, postponing or moving premieres to streaming services and sales of domestic formats fell, merchandising companies increased their annual turnover derived from their licenses. The symbiotic relationship between companies dedicated to audiovisual production and those specialized in the design of licensed products is our object of study from the history of art and design from visual culture studies. The symbiotic relationship between companies dedicated to audiovisual production and those specialized in the design of licensed products is our object of study, analyzed from the history of art and design within visual culture studies
\end{abstract}

Keywords: Cinema, Streaming services, Merchandising, Design, Covid-19.

\section{Introducción}

Después de un año 2020 en el que solo dos estrenos, Tenet (Christopher Nolan, 2020, 7.5, \$205M, $\$ 57,929,000, \$ 363,129,000) 1$ y Wonder Woman 1984 (Patty Jenkins, 2020, 5.4, \$200M \$46,257M, $\$ 166,257 \mathrm{M})$, ambas producidas por Warner Bros. Pictures, han sido capaces de mitigar las pérdidas económicas de las grandes cadenas de salas de cine de todo el mundo debido a los cierres y los aplazamientos de películas evento consecuencia directa de la pandemia mundial provocada por el Covid-19, a comienzos de 2021 será el estreno de otro blockbuster el que llene de espectadores las salas, un film de impecable factura técnica sin más pretensiones que ser un entretenimiento de primer nivel técnico y visual: Godzilla vs Kong (Adam Wingard, 2021, $6.5, \$ 200 \mathrm{M}, \$ 69,500 \mathrm{M}, \$ 357,800 \mathrm{M})$ que al cierre de este artículo todavía sigue en cartel. Lejos quedan aquellos momentos en los que podíamos asistir a espectáculos de masas con total seguridad pero estamos convencidos de que las distintas vacunas que se están administrando a la población, aunque con ritmos desiguales en todo el globo, puedan paliar esta crisis sanitaria sin precedentes en más de un siglo.

Gracias a los ingresos de Godzilla vs Kong, los cines han vuelto a abrir sus puertas y ofrecer a los espectadores otras producciones como la excelente y multipremiada Nomadland (Chloé Zhao, 2020, $7.5, \$ 5 \mathrm{M}, \quad \$ 2,143 \mathrm{M}, \quad \$ 4,820,723 \mathrm{M})$. Demostrando que el ecosistema de producciones, estrenado en la gran pantalla, se sustenta en el equilibro arte/ negocio que ofrece el medio cinematográfico, capaz de generar propuestas muy diversas, pero todas ellas necesarias, donde calidad técnica y artística, reflexión y espectáculo, evasión y compromiso social y humanismo, no son conceptos incompatibles.

En este artículo proponemos una reflexión sobre la situación actual del cine, siempre con una visión contextualizada donde el presente es resultado de eventos pasados, como un arte industrial que necesita relacionarse, estableciendo un proceso simbiótico basado en el sistema de concesión de licencias, con empresas de otros sectores para generar el capital necesario para que la rueda del sistema audiovisual siga en movimiento.

\section{1.- El cine y las necesidades de un arte industrial.}

El cine es arte pero también es industria cultural. Como bien sabemos aquellos que hemos estudiado, con mayor o menor profundidad, las Revoluciones industriales no hubiesen sido posibles sin una serie de elementos, destacando sobre el resto tecnología y capital. Toda industria necesita una inversión previa y continuada cuyo retorno y beneficio no están garantizados, es decir, los riesgos son tan altos como las posibles ganancias.

Para el profesor y analista de la imágenes Román Gubern el medio cinematográfico:

Además de ser arte, espectáculo, vehículo ideológico, fabrica de mitos, instrumento de conocimiento y documento histórico de la época y sociedad en que nace, el cine es una industria y la película es una mercancía, que proporciona unos ingresos a su productor, a su distribuidor y a su exhibidor. [...] El coste mínimo de una película es muy elevado y tiende 
a elevarse cada día más. [...] sólo una minoría de personas están en condiciones de financiar películas [...]. Y ahí nace la contradicción, dramática, entre la aventura creadora del artista y la mentalidad de quien no desea ver peligrar su inversión. Contradicción tristemente habitual que suele oponer la naturaleza del cine -formidable instrumento de cultura, de presión ideológica y propaganda para las masas a los intereses financieros que rigen los destinos de la producción. Con los problemas esbozados puede comenzar a vislumbrarse la complejidad histórica, cultural y social del fenómeno cinematográfico [...] cambiante e inestable, siguiendo las leyes de la dialéctica del progreso: [...] el hombre ha creado el cine, pero el cine está haciendo al hombre de hoy [...] constatando el papel que juega hoy el cine $[. .$.$] en el$ campo de la cultura de masas (Gubern 2014, 11-13).

De todos los sectores de la industria, el cine y la cultural en general no son los más rentables para los inversores, pero, sin embargo, ninguno es capaz de generar un prestigio social mayor. Esta es la razón por la cual las grandes fortunas destinan parte de su riqueza en proyectos culturales o sociales.

El grupo Inditex es el mejor ejemplo de que la industria textil supera en generación de beneficios económicos a la cultural, pero en un contexto social donde la preocupación por la ecología y los devastadores efectos del calentamiento global posicionarse como una de los sectores más contaminantes y que más recursos consumen no es muy positivo para su imagen de marca.

Desde sus orígenes, el cine es la mayor fábrica de mitos de la modernidad, su capacidad para transformar a personas en estrellas y a personajes en iconos de la cultura popular solo puede compararse con la industria de la música o el deporte, en su vertiente más vinculada al espectáculo. Sin embargo, la industria del cine siempre ha tenido que encontrar fuentes de financiación alternativas a los ingresos generados por la taquilla. La alargada sombra de la quiebra y los problemas presupuestarios han sido la pesadilla de aquellos soñadores que han dejado su huella artística en la Historia del séptimo arte.

Esta es la razón por la cual empresas dedicadas a la venta de productos o a la de servicios llegan a acuerdos con los propietarios de los derechos de imagen de estos iconos culturales. Al igual que en España es habitual vincular la iconografía de santos, vírgenes o del mismísimo Jesús estampando representaciones arraigadas en la tradición popular en una inmensa variedad de productos alimenticios, empresas como Inditex o Primark usan las imágenes de Darth Vader, Mickey o el emblema de la casa Stark de la serie de HBO, Game of Thrones, como reclamo en prendas de vestir, destinadas a un público global sin distinción de edad, religión, raza, ni sexo. Así se establece una relación simbiótica entre ambas empresas: mientras que el cliente adquiere un objeto que cumple su función de uso a un precio bajo, también queda satisfecha una necesidad simbólica, cumpliendo también como fetiche/ídolo/tótem de una sociedad globalizada (Mitchell, 2017,202-203).
No son pocos los historiadores que certifican que aquellos objetos que en la actualidad llamamos merchandising ya estaban presentes y a la venta en los centros religiosos de Mesopotamia y Egipto o en grandes espectáculos de masas como los J.J.O.O. de la antigüedad. Así, las mercaderías con funciones simbólicas, mágicas e identitarias han acompañado al ser humano desde tiempos remotos.

Pero si volvemos a épocas más recientes y al cine en particular, durante el siglo XX dos son los artistas/ empresarios que mejor han sabido rentabilizar esta realidad mítica: Walt Disney y George Lucas. No cabe duda de que ninguno de los dos visionarios del séptimo arte inventó el merchandising, ni que tampoco fueron los únicos en implantar este sistema para la financiación de sus proyectos, pero ambos asentaron las bases de cómo se relacionan en la actualidad las producciones audiovisuales y las empresas que comercializan productos licenciados. Esta es la razón de que la respuesta a la tesis de este artículo resida en el sigo XX, pues el presente ha contraído una deuda con su pasado más reciente que no será fácil de saldar.

\section{1.- Walt Disney: "Recuerda que todo esto comenzó con un ratón".}

Los sueños animados de Walt Disney no hubiesen sido posible sin la capacidad de su hermano para generar capital. Si Walt creó a Mickey, su hermano mayor Roy Oliver Disney, socio y cofundador desde 1923 de la Disney Brothers Cartoon, semilla empresarial de Walt Disney Company, sería el genio de las finanzas, garante de la salud económica del estudio: generando beneficios alternativos a las ganancias en taquilla que posibilitasen futuras inversiones y proyectos. Así:

A partir de 1932, la popularidad estratosférica de Mickey Mouse se tradujo en una avalancha de productos bajo licencia que reportaron pingües beneficios. En 1934, la revista Fortune publicó que las ganancias anuales de Disney derivadas de las películas y los productos de promoción superaban los 6000000 dólares, una cifra astronómica teniendo en cuenta que corría la época de la Gran Depresión. Disney reinvirtió el dinero en su estudio. Una buena parte se destinó a financiar un ambicioso programa de formación y educación que transformó el arte de la animación.

Walt se dio cuenta de que para mejorar la animación había que depurar la técnica del dibujo al máximo (Kothenschulte, 2020, 37-38).

Los hermanos Disney implantaron en la animación un sistema similar al que, pocos años antes, revolucionó la industria del automóvil de la mano del empresario Henry Ford, inspirado, a su vez, en las cadenas de despiece cárnico.

La optimización de los procesos de producción es uno de los objetivos de toda empresa, por ello, se destinan partidas económicas a programas de formación y a Investigación, desarrollo e innovación $(I+D+i)$. Si Ford optimizó el proceso de fabricación 
de sus vehículos apostando por el color negro, el único capaz de secar a una velocidad similar a la marcada por los tiempos de montaje, los hermanos Disney no dudarían en invertir parte de los beneficios en proyectos de optimización que consiguiesen una reducción significativa de los tiempos y costes de producción. Esfuerzos que dieron su fruto con la invención de la cámara multiplano patentada en 1933. Mientras este nuevo avance tecnológico revolucionaba la calidad del arte de la animación, los ingresos productos licenciados no paraban de crecer:

\begin{abstract}
A principios de los años treinta, Mickey y otros personajes de Disney ya se estaban adaptando para su uso en todo tipo de operaciones de comercialización. Docenas de compañías fabricaron artículos con la licencia del estudio. Al menos dos de ellas se salvaron de la bancarrota gracias a sus franquicias Disney (Finch, 211,78).
\end{abstract}

Antes de la producción de los largometrajes que consolidaron a Walt Disney como uno de los artistas más importantes de la Historia del cine y también del Arte, en 1935, solo con la comercialización multimillonaria de productos, su empresa disponía de un capital sólido con el que afrontar grandes retos artísticos. Según el American Exporter.

\begin{abstract}
Entre las empresas manufactureras de Estados Unidos que exportan productos con autorización de Walt Disney se encuentran cinturones Hickok, juguetes eléctricos Lionel, relojes Ingersoll, papelería Denninson, muñecos de látex Seiberling y balones de juguete Oak.

En Inglaterra se fabrica mermelada Mickey Mouse, Otros productos incluyen cubiertos, jabón, cartas, caramelos, tarjetas de regalo, relojes de pulsera, cepillos de dientes, calcetines, ligas, zapatillas, paraguas, bolsas de agua caliente, lámparas y sábanas. [...] estimando que las exportaciones de productos con licencia Disney superaron los cinco millones de dólares [solo en ese año] (Finch, 211,81).
\end{abstract}

Al igual que haría décadas más tarde haría otro cineasta/empresario, George Lucas, gracias a que las ventas de productos Disney en 1935 generaban aproximadamente unos 35 millones de dólares al año, la concesión de las franquicia del ratón rescataba de la bancarrota a empresas como las citadas trenes Lionel o relojes Ingersoll; vendiendo esta última 2 millones de relojes de Mickey en tan solo 8 semanas.

El capital generado por los productos licenciados hizo posible que, entre 1937 y 1941, Walt Disney fuese el artífice de lo que se conoce como la Edad dorada de la animación estadounidense. Aunque la decisión no solo fue artística, pues el alquiler de las películas estaba determinado por el tiempo de proyección no por su popularidad, limitando los beneficios debido a la duración de los cortometrajes. Por ello, Walt Disney decidió jugar al mismo nivel que los estudios de imagen real produciendo una serie de largometrajes de animación, algo inédito y poco sensato para muchos en aquella época. Fruto de su ambición empresarial y artística nacieron Snow White and the Seven Dwarfs (David Hand, Wilfred Jackson, Percival C.
Pearce, Ben Sharpsteen, Larry Morey, William Cottrell, 1937, 7.6, \$1,499M, \$184,925,486, \$184,925,486), Pinocchio (Hamilton Luske, Ben Sharpsteen, Wilfred Jackson, Bill Roberts, Norm Ferguson, T. Hee, Jack Kinney, 1940, 7.4 \$2,6M, \$84,254,167, \$121,892,045), Fantasia (James Algar, Samuel Armstrong, Ford Beebe, Norman Ferguson, Jim Handley, T. Hee, Wilfred Jackson, Hamilton Luske, Bill Roberts, 1940, $7.7, \$ 2,280 \mathrm{M}, \$ 76,408,097, \$ 76,411,819)$, Dumbo (1941, 7.2, \$813,000, \$1.6M) y Bambi (1942, 7.3, $\$ 858,000, \$ 102,247,150, \$ 267,447,150)^{2}$.

Pero el sueño artístico de Walt se encontró con la cruda dualidad de un medio industrial que se sustenta sobre el escurridizo capital. Así, mientras:

Blancanieves había estado en cartel en el Radio City Music Hall con las entradas agotadas nada menos que cinco semanas; Bambi solo dos.[...] Bambi se estrenó en todo el país pero con resultados igual de negativos [...] esta fantasía de la vida en el bosque creada con virtuosismo confirmó los temores de Walt, igual como había sucedido con Pinocho y Fantasía, el preestreno le hizo perder dinero. [...] No obstante, la totalidad de películas de Disney tuvieron una nueva oportunidad al final de la guerra cuando a raíz de la reapertura de los mercados de distribución nacionales e internacionales se reestrenaron (Kothenschulte, 2020, 208).

Aunque el prestigio artístico de la empresa del ratón estaba más que demostrado con las películas que se estrenaron después de su gran éxito Snow White and the Seven Dwarfs, después de la guerra Segunda Guerra Mundial:

[...] el estudio Disney dejó de ser una empresa exclusivamente de producción de animación- ni siquiera era ya la actividad principal-. El éxito de las películas de imagen real, los programas de televisión, los documentales de naturaleza y Disneyland hicieron que Walt no dedicase tanto interés a la animación. Sus películas más ambiciosas de los años de la guerra y anteriores Pinocho, Fantasía y Bambi- no habían alcanzado el éxito de Blancanieves y los siete enanitos, poniendo así fin a la gran era de exploración y obligando a recortar gastos. Las películas animadas de Disney seguían siendo las más bonitas del mundo, pero ya no estaban a la vanguardia de la animación ni de la cinematografía (Kothenschulte, 2020, 379).

Sin embargo, a Walt Disney todavía le quedaba energía creativa para producir la más ambiciosa película de animación de su carrera y de la historia del cine; para muchos su gran obra maestra: Sleeping Beauty (Clyde Geronimi, Eric Larson, Wolfgang Reitherman, Les Clark, 1959, 7.2, \$6M, \$51,6M, \$51,6M). Posiblemente la mejor película de animación de la historia, pero todo un dolor de cabeza para todos los que trabajaron en su interminable producción y para Roy Disney.

Todas estas horas de trabajo implicaban un incremento de los costes de producción. El deseo de Walt de una ilustración que emocionase supuso casi un millón de dibujos, es decir, cinco años de trabajo, y un presupuesto de seis millones de dólares, cifras 
entonces récord. A medida que aumentaban los costes, los artistas recibian cada vez más presión para terminar la película. [...] Roy se quejaba: 'Esta película está costando demasiado dinero. Se está haciendo eterna. Hay que terminarla ya'. Walt instó a las diferentes unidades a darse prisa, agarrar toda la animación preliminar, acabarla y prepararla para tinta, pintura y cámara. Básicamente lo que Walt dijo era: 'que cualquiera que sepa coger un lápiz se ponga a trabajar en esta película y acabadla' (Kothenschulte, 2020, 393).

En estas palabras queda claro la paradoja ontológica del medio cinematográfico, la perpetua lucha interna debido a su identidad dual: arte y mercancía.

Walt Disney Productions tuvo importantes pérdidas en el año fiscal 1959-1960, en gran parte debido al coste de La bella durmiente y su decepcionante recaudación en taquilla. [...] los asesores financieros presionaban a Walt para que dejase de producir largometrajes animados y se limitase exclusivamente a reestrenar los antiguos [...] que se tardaba demasiado en hacer largometrajes, que costaban demasiado y que creían que había que hacer más. Walt estuvo a punto de abandonar la animación [...] (Kothenschulte, 2020, 402-403).

Pocos años más tarde, después del éxito del largometraje de animación One Hundred and One Dalmatians (Wolfgang Reitherman, Clyde Geronimi, Hamilton Luske, 1961, 7.3, \$4M, \$144,880,014, $\$ 215,880,014)$, el 27 de agosto de 1964, Walt Disney, a sus 62 años, asistió como anfitrión al estreno de la que sería su última película, Mary Poppins (Robert Stevenson, 1964, 7.8, \$6M, \$102,272,727, $\$ 103,082,380)$, con la misma ilusión que cuando en 1937 estrenase el primer largometraje animado con sonido sincronizado, Snow White and the Seven Dwarfs, con la diferencia de que ya no era aquel joven temerario sino:

Un empresario del espectáculo, aclamado en todo el mundo, pilotando una corporación del entretenimiento internacional que, además de largometrajes animados de gran éxito, producía películas de imagen real, programas de televisión y una experiencia de ocio única en el fantástico parque Disneyland (Kothenschulte, 2020, 440).

Aunque la continuidad de su empresa estaba garantizada, el fallecimiento de Walt Disney tuvo un enorme impacto social pues él mismo se había sumido en un proceso de mitificación creando de su persona un personaje, otro icono de la cultura pop, un arquetipo a imitar por miles de niños y adultos, dejando una sensación de orfandad entre sus millones de seguidores repartidos por todo el mundo. Disney también perdía a uno de los mayores genios creativos de la historia. El talento de su hermano Roy para los negocios había sido una pieza clave para mantener el sistema en movimiento incluso en los peores momentos financieros, pero aunque el cine sea un arte industrial, no por ello es menos arte. $Y$ no hay arte sin artistas. El estudio pasaría por una larga etapa de proyectos con una factura técnica indiscutible pero carentes de la ambición, creatividad y del alma de su fundador. Estas décadas dominadas por tecnócratas financieros sumiría a la empresa en un proceso de hibernación a la espera de la aparición de jóvenes talentos. Con su llegada en las últimas décadas del siglo $X X$, Disney Company, creativamente convertida en toda una "Bella durmiente", despertaría de su letargo para nadar con The Little Mermaid (Ron Clements, John Musker, 1989, 7.6, \$40M, \$111,543,479, \$211,343,479), cantar con Aladdin (Ron Clements, John Musker, 1992, 8.0, \$28M, \$217,350,219, \$504,050,219), bailar con Beauty and the Beast (Gary Trousdale, Kirk Wise, 1991, 8.0, ) y rugir con The Lion King (Roger Allers, Rob Minkoff, 1994, 8.5, \$45,000,000, $\$ 422,783,777, \$ 1,083,720,877)$; viviendo así otra Edad dorada de la animación. El cambio de milenio estaría marcado no por la animación sino por el triunfo de una adaptación a la pantalla grande de una de las atracciones más conocidas de los parques Disney. Los avances tecnológicos en materia de VFX permitieron la fusión de las películas de acción real con animaciones hiperrealistas, llenando las grandes pantallas de seres mitológicos, monstruos y criaturas que habitaban lugares fantásticos, posibilitando el éxito de una de las franquicias más rentables de la historia de Disney, Pirates of the Caribbean (2003, 2006, 2007, 2011, 2017). Pasada la primera década del siglo XXI Disney volvería a reclamar su derecho al trono de la animación, recobrando todo su esplendor de antaño con el estreno de uno de los mayores éxitos de la cultura pop del siglo XXI: Frozen (Chris Buck, Jennifer Lee, 2013, 7.4, \$150M, \$400,953,009, $\$ 1,281,835,246)$.

El soñador Walt Disney sentó las bases de lo que sería la cultura de masas del $\mathrm{XX}$ y del $\mathrm{XXI}$, inspirando a jóvenes cineastas con gran ambición y visión empresarial, tanto con sus producciones como con sus parques temáticos. Entre ellos, un joven George Lucas que quedaría impresionado cuando asistió con su familia el día de la inauguración del parque DisneyLand en 1955, un instante que cambiaría la historia del celuloide para siempre, pues para Lucas, Disney era un ejemplo a imitar por su compromiso con la calidad. El modelo establecido por Walt Disney en el que arte e industria no eran incompatibles, sería la cimentación sobre la que George Lucas edificó su propia empresa, Lucasfilm, Ilevando a finales de la década de los 70, el 25 de mayo de 1977 y contra todo pronóstico, la fantasía a una galaxia muy, muy lejana...

\section{2.- George Lucas, un cineasta y empresario de otra galaxia.}

George Lucas, nacido un 14 de Mayo de 1944 en Modesto California, surgió del mismo movimiento de creadores cinematográficos americanos que Martin Scorsese, Peter Bogdanovich, William Friedkin y Francis Ford Coppola, su amigo y mentor. Pero a diferencia de sus contemporáneos, la aproximación de Lucas al cine tomará un camino radicalmente distinto. Mientras el resto de cineastas expresaban 
sus inquietudes intelectuales, influenciados por el cine internacional de posguerra, en guiones y películas infundidas de cinismo y fatalismo político, Lucas tomó la temprana y meditada decisión de orientar su carrera en una dirección opuesta. Su propuesta estaría más centrada en estimular los sentidos que en plantear reflexiones cerebrales, ofreciendo a los espectadores una actualización de las viejas películas de evasión mediante una apuesta personal por la innovación, desarrollo y aplicación de nuevos avances tecnológicos en todas las fases de la creación cinematográfica (Longworth, 2012, 5).

Aunque George Lucas suele ser incluido en la primera generación de directores que crecieron viendo la televisión, cuyo cine se vio "contaminado" por la influencia de las producciones desarrolladas para este medio, en realidad, la imposibilidad de su familia de disponer de un televisor hasta mediados de la década de los 50, condicionó que su principal fuente de entretenimiento durante sus primeros años fuesen los dramas radiofónicos.

A los diecisiete años fue cuando sufrió un grave accidente de coche. Su instituto permitió que se graduase a pesar de sus bajas calificaciones.

Lucas consiguió ingresar en la USC, donde conoció a muchos de los profesionales que, ante la aparente imposibilidad de entrar en Hollywood, se ayudaron unos a otros en sus proyectos personales. Todos ellos pertenecen a la primera generación de estudiantes de cine influenciada más por el cine mundial que por el canon de Hollywood. Lucas, junto con sus compañeros, dirigió su mirada hacia la French New Wave, a las películas de Fellini y también a las del maestro japonés Kurosawa, cuyas obras ejercieron una influencia decisiva sobre la serie Star Wars.

Durante los siguientes tres años Lucas hizo nueve cortos usando su propio dinero cuando superó la asignación que la USC destinaba a cada estudiante. Cuando Lucas se licenció en 1966, gracias a las competencias adquiridas por su programación docente, estaba capacitado para rodar, producir, dirigir y montar. Aunque el director estaba preparado para ser alistado en el ejército fue declarado no apto, debido a su enfermedad crónica: diabetes. Sin embargo, consiguió un trabajo como ayudante de montaje para la Agencia de Información de Estados Unidos. Pero no contento con su trabajo creando películas de propaganda militar decidió volver a su universidad.

El mayor proyecto de Lucas en la universidad fue el premiado corto Electronic Labyrinth THX 1138 4EB (1967), su corto más conocido, su experiencia en el terreno de la ciencia ficción, y la base para su primer largometraje. Pero, quizás, lo más significativo de aquellos años universitarios de Lucas fue su amistad y asociación con Francis Ford Coppola.

Coppola fichó a Lucas como ayudante en su próximo proyecto y fundó el estudio American Zoetrope para la oportunidad a jóvenes con talento.

El primer largo de Lucas, THX 1138 (George Lucas, 1971, 6.7, \$777,000 , \$2,437M, \$2,437M), profundizaba en la idea apenas esbozada en su premiado corto estudiantil. Una ópera prima, influida por la nouvelle vague, cuyo argumento y su apartado visual inspiró muchas otras producciones posteriores.

Aquí encontramos algunas similitudes con su futura saga galáctica: los soldados robots, la escena donde los soldados persiguen en sus motos al protagonista, la importancia de los efectos de sonido y de la música.

Aunque el largometraje fue bien recibido por parte de la crítica, para el público su tratamiento fue demasiado experimental, su ritmo lento y tedioso. Coppola, frustrado, se retiró a escribir el guion de la película Patton (1970), por el que recibiría el Óscar a mejor guionista. Gracias a su destreza como guionista fue elegido para rodar The Godfather (1972, 9.2, $\$ 6,000,000, \$ 134,966,411, \$ 246,120,986)$. Aunque Coppola no quería rodar una película sobre la mafia, el dinero que podría ingresar le permitiría reflotar a su estudio Zoetrope y traer del exilio a su amigo George Lucas. El rodaje de American Graffiti (1973, 7.4, \$777,000, \$115M, \$115,000,324M) en Modesto fue toda una experiencia creativa para Lucas porque ni tenían grandes estrellas ni tenían que seguir reglas externas. Si el fracaso de THX 1138 (1971) cerró las puertas de Hollywood a los nuevos talentos, el éxito de American Graffiti (1973) las volvió a abrir.

Mientras Spielberg rodaba Close Encounters of the Third Kind $(1977,7.6, \$ 20,000,000, \$ 135,189,114$, $\$ 306,889,114)$ en la que el director incluía en el reparto al propio Truffaut como homenaje, George Lucas trabajaba en Inglaterra y en un laboratorio de California en la más ambiciosa película de serie $B$ de alto presupuesto de la historia. Gracias al éxito de su anterior película, la Fox le había asignado un presupuesto, elevadísimo para la época, de 13 millones de euros. Aunque el estudio, al principio, se negó a cederle los derechos para que Lucas pudiese hacer las secuelas, éste se mantuvo firme. Así se aseguró el control creativo del proyecto y de sus secuelas. Incluso llegó a afirmar que ganarian más dinero con las ventas de juguetes que The Godfather (1972) con la taquilla.

Lucas también insistió en tener los derechos de la música y las ganancias de las ventas del álbum de la banda sonora, y también los derechos de las posibles segundas partes. Y, en último lugar, aunque no con menos insistencia, pidió los derechos del merchandising, la comercialización de los productos relacionados con la película. Hasta La guerra de las galaxias, este aspecto era una fuente de ingresos relativamente menor.[...] Recuerda Milius: 'George me dijo: 'Voy a ganar cinco veces más que Francis con estos juguetes de ciencia ficción. $Y$ no tendré que hacer El padrino. 'Yo pensé: ¿De dónde vendrá esto?' Lucas había estudiado todos los aspectos. No se hacía ilusiones sobre la clase de película que estaba haciendo. 'He hecho la que considero la película más convencional que posiblemente soy capaz de hacer. Es una de Disney. Todas las de Disney recaudan dieciséis millones; por lo tanto, ésta va a recaudar dieciséis millones. Costó diez, y por eso vamos a perder dinero en el estreno, pero espero recuperar algo con los juguetes' (Biskind, 2008, 485-486). 
Cuando Star Wars (George Lucas, 1977, 8.6, \$11M, $\$ 460,998,507, \$ 775,398,007)$ se estrenó el público enloqueció. Star Wars era algo más que una película, se había convertido en un fenómeno social. Los estudios habían vuelto a encontrar la fórmula del éxito y a conectar con los intereses del público.

El merchandising de La guerra de las galaxias había resurgido y bastaría para mantener a Lucasfilm alejado de los números rojos durante años, si no décadas. Solo los productos derivados del Episodio III (2005) recaudarian más de 3000 millones de dólares en todo el mundo, y Hasbro vio cómo sus beneficios daban un salto del $15 \%$ montado en el carro de los juguetes de la saga. A estas alturas, los fans compraban casi cualquier figurita relacionada con el universo de La guerra de las galaxias [...] ( Jones, 2017, 513).

Aunque no son pocos los críticos que defienden que Star Wars (George Lucas, 1977) es una buena película, pero mejorable, como demostró Star Wars: Episode V - The Empire Strikes Back (Irvin Kershner, $1980,8.7, \$ 18,000,000, \$ 292,753,960, \$ 538,375,067$ ), o como pudo haber sido Star Wars: Episode VI Return of the Jedi (Richard Marquand, 1983, 8.3, $\$ 32,500,000, \$ 309,306,177, \$ 475,106,177)$ sin sus exigencias de infantilizarla, incluyendo a los ewoks, y que incluso desde el punto de vista cinematográfico no está a la altura de sus dos películas anteriores, lo que nadie duda es que dentro de ella todo funciona. Aunque todos los departamentos que trabajaron en la producción se implicaron al máximo, no cabe duda de que el talento para el montaje, que desde sus inicios impregna toda la trayectoria del director, es la clave de que todas las piezas del puzle encajen a la perfección. Además, Lucas se atrevió, en tiempos en el que la ciencia ficción se había vuelto seria, a reivindicar un género denostado por la crítica: la space opera. El premio a su osadía no fue otro que el más rotundo éxito de público y de buena parte de la crítica.

[...] para filmar El imperio contraataca, la continuación de La guerra de las galaxias. Tras recoger el testigo de Coppola, su mentor, el grandioso plan de Lucas incluía, por supuesto, la independencia financiera de los estudios. Quería financiar él mismo El imperio contraataca, e insistió en tener un cincuenta por ciento $\mathrm{y}$, después, un setenta y siete por ciento del gross - un porcentaje sin precedentes - tras superar un umbral previamente fijado; quiso también la propiedad del negativo y los derechos para televisión y el merchandising. [...] La guerra de las galaxias [...] demostró que era posible hacer una película de gran éxito a partir de una idea original, y despertó en los estudios la conciencia del potencial del merchandising, ya que quedó demostrado que la venta de libros, camisetas y muñequitos podía ser una importante fuente de ingresos. El merchandising de La guerra de las galaxias, en lugar de limitarse a promover la película, como se había hecho siempre hasta ese momento, adquirió «vida propia» y consiguió más de tres mil millones en licencias en el momento del reestreno de La guerra de las galaxias (1997), lo cual fue un incentivo más para reemplazar los personajes complejos con sencillos muñecos y estereotipos que luego se podían convertir fácilmente en juguetes. Además de su impacto en las técnicas de márketing y merchandising, La guerra de las galaxias tuvo un profundo efecto cultural

(Biskind, 2008, 518-519).

Después de Star Wars (1977), George Lucas no volvió a dirigir otra película hasta 22 años más tarde. Aunque no son pocos los que dicen que se concentró más en su faceta de empresario, que se acomodó y se dedicó a vender muñecos, quizás no tanto por su falta de interés artístico sino por sus serios problemas de salud, los cuales le impedían soportar el duro proceso físico y mental al que están sometidos todos los directores. Por ello, decidió concentrar sus esfuerzos en labores de producción, en ayudar a los amigos, y en empresas que cambiarían en profundidad todas las fases del cine.

En los años entre la primera trilogía y las precuelas, George Lucas impulsó su empresa Industrial Light \& Magic cambiando las técnicas visuales del cine, pero también del resto de producciones audiovisuales, desde finales del siglo pasado hasta comienzos del siglo XXI. Muy importantes, en este periodo, fue su implicación, a través de sus empresas, de nuevos sistemas de sonido como el sistema de sonido THX, la animación, o los videojuegos. La división informática de George Lucas, adquirida por Steve Jobs, se convertiría en la empresa mundialmente aclamada, tanto por la crítica como por el público, dedicada al cine de animación 3D, Pixar. Cuya exitosa carrera ha cumplido más de 25 años. Además, George Lucas utilizó su influencia, y su dinero, para acudir al rescate de empresas como Marvel cómics o Lego, salvándolas de la bancarrota con el merchandising de Star Wars, al igual que hizo Walt Disney a comienzo de los 30 con empresas americanas.

Steven Spielberg usando a la ILM, empresa fundada por George Lucas, realizó la película, Jurassic Park $(1993,8.1, \$ 63 \mathrm{M}, \$ 404,214,720, \$ 1,033,928,303)$ que supuso un punto de inflexión en el uso de las técnicas CGI. Allí encontró George Lucas el camino para volver a la dirección. Ya no tendría que soportar los rigores de un rodaje, podría grabar a los actores en el estudio frente a una pantalla verde y recrearlo todo usando el ordenador.

El resultado de décadas de espera y desarrollo tecnológico fue una nueva trilogía del universo Star Wars, tres precuelas: Star Wars: Episode I The Phantom Menace (George Lucas, 1999, 6.5, $\$ 115,000,000, \$ 474,544,677, \$ 1,027,082,707)$, Star Wars: Episode II - Attack of the Clones (George Lucas, $2002,6.5, \$ 115,000,000, \$ 310,676,740, \$ 653,779,970$ ) y, quizás la mejor de todas, Episodio III: La venganza de los Sith (George Lucas, 2005, 7.5, \$113,000,000, $\$ 380,270,577, \$ 868,390,560)$, una puesta en valor de los avances en el desarrollo de imágenes y sonido digital que introdujeron al medio cinematográfico y al resto de las producciones audiovisuales en el siglo $\mathrm{XXI}$, consiguiendo unas recaudaciones millonarias en taquilla y unos beneficios aún mayores con la venta de productos licenciados. Sin embargo, estas películas fueron masacradas por la crítica especializada y 
provocaron el primer gran ciberenfado, plasmado en el documental The People vs. George Lucas (2010), de una comunidad de fans globalizada y organizada no solo de forma física sino también mediante las recién nacidas redes sociales.

Disney compró Lucasfilm Ltd. en 2012 incluidas las franquicias de Star Wars e Indiana Jones por 4.050 millones de dólares, como antes hizo con Pixar en 2006 por 7.400 millones de dólares o en 2009 con Marvel Entertainment por 4.000 millones de dólares. Inversiones muy rentables teniendo en consideración los beneficios generados por la explotación de los derechos de todas las franquicias asociadas a estas empresas. Pero para vender licencias Disney produjo un trilogía que continuaba los episodios originales de George Lucas y dos spin off con resultados muy desiguales de crítica y público: Rogue One (Gareth Edwards, 2016, 7.8, $\$ 200 \mathrm{M}, \$ 532,177,324, \$ 1,056,057,720)$, para muchos críticos y fans la mejor película del universo Star Wars desde los Episodios IV-V; y, la innecesaria, Solo: A Star Wars Story (Ron Howard, 2018, 6.9, \$275M, $\$ 213,767,512, \$ 392,924,807)$.

El éxito de Star Wars: Episode VII - The Force Awakens (J.J. Abrams, 2015, 7.9, \$245M, $\$ 936,662,225, \$ 2,068,455,661)$ fue incontestable. Sin embargo, algunos críticos, que habian "crucificado" a George Lucas durante todos estos años, reconocieron que Abrams solo había aplicado la misma fórmula utilizada en La guerra de las Galaxias (1977), admitiendo que, a pesar de lo malas que fueron las precuelas, al menos fueron producto de un artista que deseaba ser original y no repetirse.

Sin embargo, Star Wars: Episode VIII - The Last Jedi (Rian Johnson, 2017, 7.0, \$317,000,000, $\$ 620,181,382, \$ 1,332,698,830)$ provocó un cisma entre los críticos y los fans de Star Wars que incluso querían que la película se hiciese de nuevo, todo un fenómeno de hater histeria generalizada similar a lo que ocurriría con la última temporada de Game of Thrones. Una reacción que tuvo sus efectos en una considerable disminución de las ventas de merchandising.

Disney intentó recuperar el favor de los fans con Star Wars: Episode IX - The Rise of Skywalker (J.J. Abrams, 2019, 6.6, \$275M, \$515,202,542, \$1,074,144,248) pero solo consiguió poner en valor la trilogía precuela de George Lucas, al que muchos pasaron de querer echarlo a la hoguera a demandar su vuelta.

Aunque el talento, la capacidad o la ambición artística de este director puedan cuestionarse, lo que es irrefutable es que si Georges Méliès nos llevó a la Luna, George Lucas transportó a una galaxia lejana. Walt Disney y George Lucas cambiaron el arte del medio audiovisual para siempre, transformando los procesos de producción, la manera de hacer cine y de verlo, de sentirlo.

\section{2.- La relación de las producciones audiovisuales con el merchandising en la actualidad.}

Entre el año 2000 y el 2020 se produce la imposición de lo digital, un cambio de paradigma cultural y social
, finalizando la transición de lo analógico a un sistema híbrido, situado entre los dos mundos, para terminar en un mundo binario, afectando este cambio a todas las esferas que conforman el ecosistema de las producciones audiovisuales.

En 2020, una pandemia sanitaria global sitúa a todos los países al borde del colapso. Mientras las cifras de fallecidos alcanzan límites insostenibles y buena parte de los líderes mundiales demuestran una vez más su incompetencia histórica, la comunidad científica busca una vacuna. Los cines de todo el mundo, ante la falta de unos espectadores confinados en casa por los Gobiernos, cierran. Sin embargo, el consumo de productos de ocio o culturales, desde películas hasta series o música, sufre un crecimiento exponencial propiciado por las plataformas streaming. Todo ello sin salir de casa: el Hombre vuelve a la falsa seguridad de la caverna.

El cine, el arte industrial por antonomasia, inseparable ontológicamente de la tecnología desde hace su aparición hace más de un siglo, continúa mutando a cada paso, incrementando su velocidad en cada vuelta de su danza espacial.

Una relación de beneficio mutuo fruto de su condición dual, en la que arte y técnica se retroalimentan, produciendo una espiral de crecimiento, alimentado por la sinergias producidas en cada giro, alcanzando, en las dos últimas décadas, un ritmo frenético, siendo reflejo y espejo de la sociedad especular que lo recepciona.

Este medio y sus "hijos y nietos reconocidos" (la televisión analógica a las plataformas digitales streaming; el videoclip; los videojuegos 0 los contenidos emitidos por los social media) asentado entre el arte (lo eterno) y la tecnología (lo efímero) entre 1999 y 2020 ha completado uno de sus giros más significativos: la transición de la imagen analógica a la digital. Un cambio de paradigma que ha sido posible gracias a los dos cineastas y empresarios tratados en el apartado anterior que invirtieron una parte muy importante de sus beneficios, la mayoría de los cuales derivados de los productos licenciados, en empresas de desarrollo tecnológico aplicados al cine, pero que han traspasado las pantallas y transformado nuestra realidad.

Esta transición solo ha puesto de manifiesto que el ecosistema de las producciones audiovisuales se estructura como un sistema de red donde el arte reside de manera distribuida, no uniforme, sin permanecer estático, a veces concentrado y otras diluido al mínimo como si de un perfume se tratase.

En este contexto, el cine actual quiere ser serial, sirva de ejemplo las 23 películas con continuidad argumental del Universo Cinemático Marvel (MCU) estrenadas en pantalla grande entre 2008 y 2019, las nuevas entregas de la franquicia Star Wars y sus spin off, la adaptación de sagas literarias como Harry Potter o El Señor de los Anillos y El Hobbit, y las series quieren ser cine, Game of Thrones (2011-2021) con varios capítulos de más de una hora de duración con batallas que superan a las vistas en la Trilogía del Señor de los Anillos de Peter Jackson. Pero los 
presupuestos y los tiempos de producción de ambos medios no son comparables. El espectador es ajeno a estas cuestiones, aunque los documentales y los libros se empeñen en profundizar en cuestiones de desarrollo, y esto provoca multitud de equívocos, enfados y decepciones que afectan a las ventas de merchandising. El caso de la serie Game of Thrones, todo un fenómeno cultural de la segunda década del siglo XXI también nos sirve para tratar esta relación entre las producciones audovisuales y el merchandising. Pues es el mejor ejemplo de lo que ocurre cuando, por ambición artística, una serie producida por una plataforma para abonados, en este caso $\mathrm{HBO}$, lucha con las limitaciones presupuestarias del medio. Juego de Tronos es la serie que quiso ser cine y lo consiguió, aunque muchos fans no sean capaces de apreciarlo.

Según nos cuenta James Hibberd en uno de sus libros, HBO no lo tuvo fácil cuando decidió producir la serie Game of Thrones, pues las negociaciones sobre los derechos de Canción de Hielo y Fuego demoraron el proyecto más de un año. $\mathrm{Y}$ con respecto al tema que en este artículo nos ocupa, esclarecedoras son las palabras de su autor:

El gran escollo fue el merchandising. Al principio no sabíamos que iba a ser un éxito, pero los abogados de HBO no querían sentar el precedente de renunciar a algo que nunca antes habían cedido. Yo les decía: «No puedo daros todo lo que queréis. Ya tengo un videojuego y un juego de rol en producción. Ya he cedido a un tío los derechos para hacer réplicas de las monedas». ¿Quién podía saber que las monedas de Juego de tronos iban a triunfar? Así que nos metimos en una negociación interminable analizando un objeto tras otro, en plan: «Vosotros os lleváis los muñequitos cabezones, yo me quedo los llaveros...» (Hibberd 2021, 28).

Durante 10 años el progresivo impacto social de Game of Thrones estuvo emparejado con el éxito de los productos licenciados cuyos beneficios financiaban temporada tras temporada. Según James Hibberd, periodista y actual editor de la revista especializada Entertaiment Weekly:

El merchandising se disparó al mismo ritmo y HBO aprobó docenas de productos oficiales. Se comercializaron cervezas artesanas de Juego de tronos, vinos, muñecos cabezones, tazas, figuras, juegos y muchísimas camisetas [...]

(Hibberd 2021, 307).

Aunque no hay duda de que el éxito de ventas de los productos licenciados de la serie ha propiciado que HBO aumente su inversión temporada tras temporada, el descontento generalizado con un final que ha dejado a muy pocos seguidores satisfechos ha supuesto una disminución drástica de las ventas de estos productos condicionando el futuro de posibles secuelas o spin off. En el panorama audiovisual actual no debería extrañarnos que después de la finalización o cancelación de una producción el interés de los espectadores/consumidores de productos relacionados decaiga, pues los canales streaming propician, con su política de fidelización y de incremento de abonados, un marco dominado por lo efímero, lo transitorio, lo fugaz, donde la novedad es la única constante.

Marvel Studios compensa la larga y necesaria espera, entre una entrega y la siguiente, estrenando varias producciones al año, mientras, las series, como es el caso de Game of Thrones, reducen al mínimo el número de episodios y alargan la duración de los mismos a más de una hora de metraje.

Si bien en el contexto de la pandemia provocada por la Covid-19, los estudios han llevado sus producciones cinematográficas al terreno de las mini series con capítulos de una duración inusual e irregular inédito la historia de la pequeña pantalla, estrenándolas como atrayentes de su plataforma Disney + , The Mandalorian (Jon Favreau, 2019-2020, 8.8) con 2 temporadas de 8 capítulos, de duración entre 31-52 minutos, cada uno), WandaVision (Jac Schaeffer, 2021, 8.1) de 9 episodios de entre 29-46 minutos, The Falcon and the Winter Soldier (Kari Skogland, 2011, 7.9) con 6 episodios de 47-61 minutos a la espera del estreno del último.

$Y$ estos cambios tienen un impacto calculado en la venta de productos licenciados: aumentan las empresas que adquieren licencias, las ventas crecen de manera exponencial y, con los cines cerrados, estos son los únicos ingresos ( a los que añadimos las suscripciones y la venta de formatos domésticos).

$\mathrm{Y}$ aunque dentro de las producciones audiovisuales, pues ya no solo estamos hablando solo del cine, hay ciertos géneros más proclives, como el caso de la fantasía, la ciencia ficción con carácter más evasivo o los superhéroes, cualquier género puede tener la posibilidad de generar grandes beneficios añadidos por licencias. Series como The Simpsons (1989, 32 temporadas), Breaking Bad (2008-2013, 5 temporadas), Big Bang Theory (2007-2019, 12 temporadas), The Crown (2016, temporada 4), The Handmaid's Tale (2017, 3 temporadas), Bridgerton (2020, 1 temporada), todas con gran éxito de crítica y público, ofrecen a sus millones de seguidores una ingente variedad de productos. Y el fenómeno social causado por una excelente serie protagonizada por una ajedrecista, encarnada por la actriz Anya Taylor-Joy, titulada The Queen's Gambit (Scott Frank, 2020) ha disparado la afición por un deporte no precisamente en alza, agotándose todos los productos licenciados asociados, desde libros a muñecos de la marca Funko, hasta el último tablero con piezas que acumulaba polvo en cada tienda del país y del mundo. Las revistas de ajedrez con la seductora imagen de la actriz frente a un tablero han conseguido aumentar sus ventas y personas de todas las edades se han federado o inscrito cursos de iniciación a este deporte no precisamente de masas. Este es el mejor ejemplo de cómo las producciones audiovisuales de calidad pueden transformar la sociedad, pues la potencia de sus imágenes traspasa la pantalla e irradia no solo a una serie de productos y servicios sino que modifica, en este caso para bien, los comportamientos de la población. Esta es la magia del cine: ser capaz de 
transformar la sociedad en un lugar mejor, cuestión y utopía que las vanguardias históricas no consiguieron; y también la justificación que esgrimen muchos para considerarlo un arte menor, en un intento de banalización de algo que ni dominan, ni comprenden, que escapa de su control, provocándoles miedo y repulsión. Ambos posicionamientos tanto el apocalíptico como el integrado están cargados de argumentos, por ello, siguiendo los pasos del maestro Umberto Eco, nos posicionaremos en un terreno intermedio pero nunca neutral, intentando, desde nuestra posición académica y humanista, inclinar la balanza hacia el lado más beneficioso para todos, cumpliendo nuestro compromiso con una sociedad que necesita una serie de herramientas que les permitan reflexionar sobre éstas y otras cuestiones relacionadas con los medios de masas, generando pensamientos propios que conduzcan a comportamientos que los enriquezcan como individuos.

Aunque el cine y las series siempre serán medios independientes esto no quiere decir que desde el punto de vista artístico existan criterios artísticos absolutos que los limiten, ya Twin Peaks (Mark Frost, David Lynch, 1990-1991,8.8 ) demostró que una serie pueden ser superior artísticamente a la inmensa mayoría de películas estrenadas.

Es curioso que el mismo día que se celebra el estreno hace una década de Game of Thrones (2011-2019, 8 temporadas), el 17 de abril de 2011, los principales portales de información internacionales publican que el presupuesto que Amazon ha destinado a su próxima serie ambientada en el universo de Tolkien tendrá un presupuesto de 500 millones de dólares para su primera temporada. Un hecho insólito que pone de manifiesto la importancia que tiene en la relación entre las producciones audiovisuales y el merchandising, los distribuidores, ejerciendo una influencia capaz de fortalecer o destruir esta relación entre el cine, el merchandising y los prosumidores. En esta lucha de gigantes, Disney (Pixar, Lucasfilm, Marvel Studios) Warner, Sony, Netflix, HBO Max - Amazon tienen todavía mucho espectáculo que ofrecer, pues talento, ambición y, sobre todo, capital no les falta.

\section{Conclusiones.}

La relación entre el arte industrial del cine y el merchandising, un sistema de objetos diseñados bajo licencia, es cada vez más fuerte debido a los cambios experimentados en estos tiempos de la hipermodernidad ${ }^{3}$, en la sociedad de la seducción y la emoción (Lipovetsky, 2020,4), conformada por prosumidores cuya identidad global se asienta sobre la mitología de la cultura pop.

Con la actual seriefilia la relación entre las producciones audiovisuales y el merchandising crece de manera exponencial debido a las relaciones simbióticas entre los agentes implicados en esta estructura de red y a las sinergias que benefician a todas las partes. Las limitaciones presupuestarias de series estrenadas en servicios para abonados necesitan más que el cine los beneficios generados por las licencias. Series que han batido todos los registros de descargas ilegales pueden beneficiarse de los productos licenciados que estos "espectadores piratas" compran casi de manera compulsiva. Así algunas series o películas se asimilan a anuncios publicitarios, de dos horas o más de duración, que sirven para vender productos.

Así, la cultura pop del siglo XXI, hija de la cultura transmedia (Scolari 2013), globalizada y digital de la cultura de masas tan criticada por Guy Debord o explicada por Theodor Adorno, Roland Barthes, Jean Baudrillard, e incluso aplaudida por McLuhan con su "aldea global", rompe con cualquier límite y jerarquía de las artes o el diseño, pues su interés por la democratización diluye cualquier barrera, no desperdicia nada, conformando un sistema que absorbe cualquier paradoja y no siente incomodidad alguna en ser alta y baja cultura, arte y negocio. ${ }^{4}$

\section{Notas finales}

${ }^{1}$ En las referencias a algunas producciones audiovisuales hemos incluido en este articulo una serie de datos que consideramos de interés, después del año de estreno, separados por comas figuran la valoración IMDB, el presupuesto, la recaudación en taquilla USA, los ingresos en la taquilla global, siendo los datos económicos expresados en millones de dólares. Fuente: IMDB.

${ }^{2}$ Los ingresos de taquilla USA e internacional se refieren a la suma de las recaudaciones tanto del estreno como de los reestrenos a lo largo de casi un siglo. Fuente: IMDB.

${ }^{3}$ Los términos hipercine, tiempos hipermodernos, etc. son muy utilizados en toda la obra del filósofo francés Gilles Lipovetsky.

${ }^{4}$ Agradecemos a la Universidad de Málaga el contrato predoctoral con el Departamento de Historia del Arte 2021/2022 que ha posibilitado esta publicación y su comunicación.

\section{Referencias bibliográficas.}

Biskind, Peter. 2008. Moteros tranquilos, toros salvajes. La generación que cambió Hollywood, Barcelona, Anagrama.

Finch, Christopher. 2011. El Arte de Walt Disney. De Mickey Mouse a Toy Story. Barcelona, Lunwerg.

Hibberd, James. 2021. Todos los hombres deben morir. Barcelona. Plaza \& Janés.

Jones, Brian. 2017. George Lucas. Una vida. Barcelona, Reservoir Books.

Lipovestky, Gilles. 2020. Gustar y emocionar. Barcelona. Anagrama.

Mitchell, W.J.T. 2017. ¿Qué quieren las imágenes? Victoria-Gasteiz, Sans Soleil Ediciones.

Kothenschulte, Daniel. 2020, Los Archivos de Walt Disney: sus películas de animación - 40Th Anniversary Edition. Madrid. Taschen.

Longworth, Karina. 2012. Masters of Cinema: George Lucas, New York, Phaidon.

Sandhaus, Louise. 2016. Conversaciones con George Lucas. Ocaso o despertar de un Mito, Salamanca, Confluencias. 